\title{
High Cesarean Section Rates in Latin America, a Reflection of a Different Approach to Labor?
}

\author{
Eghon Guzman $^{1}$, Jack Ludmir ${ }^{2}$, Mark DeFrancesco ${ }^{3}$ \\ ${ }^{1}$ Hospital Dr. Sotero del Rio, Integramedica Bupa, Santiago, Chile \\ ${ }^{2}$ Department of Obstetrics and Gynecology Perelman, School of Medicine at the University of Pennsylvania and \\ Pennsylvania Hospital, Philadelphia, PA, USA \\ ${ }^{3}$ Department of Obstetrics and Gynecology, University of Connecticut, Farmington, CT, USA \\ Email: ${ }^{*}$ eguzmanb@gmail.com
}

Received 22 May 2015; accepted 26 July 2015; published 31 July 2015

Copyright (C) 2015 by authors and Scientific Research Publishing Inc.

This work is licensed under the Creative Commons Attribution International License (CC BY).

http://creativecommons.org/licenses/by/4.0/

(c) (i) Open Access

\begin{abstract}
Increasing rates of cesarean section, as high as $\mathbf{5 0 \%}$ in some countries in Latin America, compared with the US and the rest of the world, demand a closer analysis of its causes and implications. The significant morbidity for both mother and baby associated with cesarean section requires immediate action from national and international societies to confront the situation with specific solutions, including patient education. We recommend a consensus meeting of Latin American ACOG (American College of Obstetricians and Gynecologists) section members to address the issue and to consider adopting guidelines based on evidence and reflecting the realities of the countries involved.
\end{abstract}

\section{Keywords}

\section{Cesarean Section Rates}

\section{Introduction}

Cesarean section is the most common surgical intervention in the world. In 2010, there were a total of 128 million births in the world, and of those 18.5 million (14.45\%) were delivered by cesarean section [1]. It is a paradigm that historically birth by cesarean is developed to save the mother's life and these days it is performed in many circumstances to save the baby. Although in 1985, a group of experts for the World Health Organization

\footnotetext{
${ }^{*}$ Corresponding author.
}

How to cite this paper: Guzman, E., Ludmir, J. and DeFrancesco, M. (2015) High Cesarean Section Rates in Latin America, a Reflection of a Different Approach to Labor? Open Journal of Obstetrics and Gynecology, 5, 433-435. 
stated that the optimal cesarean section rate should be $15 \%$, there was not an ideal rate based on evidence. The incidence of cesarean varies tremendously from country to country and on various continents. In countries in Sub-Saharan Africa, where the cesarean rates are very low, many women die from obstetric complications or suffer permanent damage from obstructed labor. In Norway and Japan, the cesarean section rate is as low as $16 \%$ to 17\% compared with 37\% to $43 \%$ in Latin American countries such as Chile, Mexico and Brazil [1] [2]. It has been stated that the difference in rates between developed countries is based on the different approaches towards labor and delivery. Countries with a less "medical" or less "interventional" approach have lower rates, compared with countries that have more of a "medical" or "interventional" approach.

Chile, one of the most developed countries in Latin America and a member section of ACOG, faces many of the issues seen in the US related to cesarean delivery. Nevertheless, it has a cesarean rate of $40 \%$ for the population attending hospitals of the public sector, and $70 \%$ cesarean section rates for women attending private clinics; in addition almost all deliveries in private clinics are done by physicians. In these clinics, a "medical" approach toward labor and delivery prevails [3]. However, the increase in cesarean rates has not resulted in better neonatal outcomes.

The purpose of this paper is to discuss possible strategies to address the rising rates of cesarean section in Latin America.

\section{Reasons behind the Increase in Cesarean Sections}

Many reasons have been responsible for the high rates of primary cesarean delivery seen in Latin America including: a) The use of continuous electronic fetal heart rate monitoring instead of intermittent auscultation for low risk deliveries, resulting in increase cesarean rates for false positive results without benefit for the baby. b) The high rate of elective inductions prior to 39 weeks gestation resulting in cesarean birth (almost 40\%) in which dystocia is given as the primary diagnosis for cesarean delivery [3]. c) The public misconception that cesarean birth is better for babies. d) Better remuneration for cesarean birth compared to vaginal delivery in some of these countries. e) Fear of litigation. f) Other common reasons include: infertility, advanced maternal age, presence of cord around the fetal neck during sonography, prematurity, breech position and concerns of maternal pelvic floor damage with vaginal delivery

In multiparous women, repeat cesarean section is responsible for over $50 \%$ of sections in these patients. It is clear that Chile, as an example of many other Latin-American countries that are becoming more developed through the years, has adopted many of the great advances in obstetrics that we have seen in the last decades. Unfortunately it also has inherited many of the disadvantages seen in the US including the use and abuse of cesarean delivery due to excessive interventionism or for reasons lacking firm evidence.

In Latin America, the fear of malpractice litigation for not performing a timely cesarean delivery has increased in the last few years. In many countries physicians lack malpractice insurance and demands can result in criminal penalties instead of civilian financial reparation. Unfortunately the media and lack of public education has resulted in physicians performing cesarean in every patient for fear of litigation.

\section{Patient Autonomy and Patient Education}

In the last few decades, women in Latin America like in the rest of the developing world are demanding more independence and autonomy and more choices in their reproductive decisions. Many are postponing having a child to later reproductive years due to professional desires and many are having only one child. The ethical principle of autonomy when confronted with maternal request for elective cesarean delivery should be balanced with the ethical principle of nonmaleficence. Patients should be counseled and educated about five possible complications from cesarean delivery based on moderate evidence including: greater risk for hemorrhage, longer maternal length of stay, higher neonatal morbidity (in particular respiratory), malplacentation (with greater risk of placenta accreta, previa and abruption in next gestation) and uterine rupture in subsequent deliveries [4]-[6].

\section{Possible Solutions}

As a response to similar situations regarding cesarean delivery, in the US, where in 2012 one in three women who gave birth was by cesarean section, a recent Obstetric Care Consensus by ACOG and the Society of Maternal Fetal Medicine (SMFM) discussed strategies to safe prevention of primary cesarean section in response to 
the common indications for primary cesarean delivery including dystocia, abnormal fetal heart rate tracing, fetal malpresentation, multiple gestation and suspected fetal macrosomia [4]. Recommendations include revisiting the definition of labor dystocia based on new evidence of a slower rate of labor progression, standardization of fetal heart rate interpretations, nonmedical interventions such as support during labor, and the use of external cephalic version and trial of labor for breech presentation and twin gestations.

ACOG recommends a trial of labor for those women that have a history of a low transverse cesarean section regardless of the prior indication, because of the small risk of uterine rupture of less than one percent [7].

Furthermore, on the topic of cesarean upon maternal request, the College states that in the absence of maternal or fetal indications, a plan for vaginal delivery is safe and appropriate. Cesarean section on maternal request should not be motivated by the unavailability of effective pain management, and cesarean delivery on maternal request should not be recommended for women desiring several children due to increase risks for malplacentation [5].

Although we respect patient autonomy and the desire of some women to plan their delivery including elective cesarean section, patients should be extensively counseled regarding the risks of cesarean including neonatal morbidity and possible significant maternal morbidity secondary to malplacentation in subsequent gestations.

\section{Conclusions}

As obstetrician gynecologists with a keen interest in Latin America, and as members of the American College of Obstetricians and Gynecologists (ACOG), we are concerned by the continued increase in cesarean rates in Latin American countries, and by the lack of any systematic approach at the national and/or continental level to try to address this issue. We also know many of our Latin American colleagues share our concerns.

We believe that it is time to find solutions in conjunction with these countries to confront the rapid and extremely high rate of cesareans delivery seen not only in the private sector but in public hospitals and low-resource populations. We suggest that we convene a meeting of our Latin American ACOG members to create the consensus in regards to the high cesarean section rates in Latin American countries, similar to the NIH consensus group convened in 2006 in the US, and that we consider adapting some of the recommendations that ACOG and SMFM have published to our realities. We believe that the public in general has to be educated about labor and delivery and the false myth that elective cesarean delivery is better for mother and baby.

We strongly believe that advocacy for our patients and their well being is of paramount importance and that our approach to the Latin American laboring patient should be humane, supportive and based on evidence. Only in this way we will improve the health and quality of our patients and their children.

\section{References}

[1] Gibbons, L., Belizan, J.M., Lauer, J.A., Betran, A.P., Merialdi, M. and Althabe, F. (2010) The Global Numbers and Costs of Additionally Needed and Unnecessary Cesarean Sections Performed per Year: Overuse as a Barrier to Universal Coverage. World Health Report 2010, Background Paper, 30.

[2] Gibbons, L., Belizan, J.M., Lauer, J.A., Betran, A.P., Merialdi, M. and Althabe, F. (2012) Inequities in the Use of Cesarean Section Deliveries in the World. American Journal of Obstetrics \& Gynecology, 206, e1-e19. http://dx.doi.org/10.1016/j.ajog.2012.02.026

[3] Guzman, E. (2012) Epidemiological Profile of Caesarean Section in Chile in the Decade 2000-2010. Medwave, 12, e5331.

[4] Safe Prevention of the Primary Cesarean Section Delivery (2014) Obstetric Care Consensus No. 1. American College of Obstetricians and Gynecologists. Obstetrics \& Gynecology, 123, 693-711. http://dx.doi.org/10.1097/01.AOG.0000444441.04111.1d

[5] Cesarean Delivery on Maternal Request (2013) Committee Opinion No. 559. American College of Obstetricians and Gynecologists. Obstetrics \& Gynecology, 121, 904-907. http://dx.doi.org/10.1097/01.AOG.0000428647.67925.d3

[6] Many, A., Helpman, L., Vilnai, Y., Kupfermic, M.J., Lessing, J.B. and Dolberg, S. (2006) Neonatal Respiratory Morbidity after Elective Cesarean Section. The Journal of Maternal-Fetal \& Neonatal Medicine, 19, 775-778. http://dx.doi.org/10.1080/14767050500333868

[7] Vaginal Birth after Previous Cesarean Delivery (2010) Practice Bulletin No. 115. American College of Obstetricians and Gynecologists. Obstetrics \& Gynecology, 116, 450-463. http://dx.doi.org/10.1097/AOG.0b013e3181eeb251 